\title{
PEMANFAATAN KNOWLEDGE DATA DISCOVERY(KDD) PADA POLA PERMAINAN ATLET BULUTANGKIS
}

\author{
${ }^{1}$ Luki Ardiantoro , ${ }^{2}$ Soffa Zahara, ${ }^{3}$ Nani Sunarmi \\ ${ }_{1,2,3}$ Program Study T. Informatika, FT, Universitas Islam Majapahit \\ 'ipan.ardianto@gmail.com,2sofa.zahara@gmail.com, ${ }^{3}$ nani_sunarmi@gmail.com
}

\begin{tabular}{l|l|l} 
Received : April 2019 & Accepted : Mei 2019 & Published : Juni 2019
\end{tabular}

\begin{abstract}
Knowledge Discovery in Data Base (KDD) is an interdisciplinary area focusing upon methodologies for extracting useful knowledge from data (base). FP-growth widely used to analyze data pattern from amount huge of data with frequent repeated items. In this research, this algorithm used to analyze in a sport activity, badminton. Specifically, the algorithm use to identify and considering frequent item set from particular technical stroke during the game. Finally, sport science is a must for Indonesia to win major tournament. This is our concern in this research.
\end{abstract}

Keywords: KDD, FP Growth algorithms, Badminton

\begin{abstract}
ABSTRAK
KDD merupakan kegiatan interdisiplin ilmu yang mengacu kepada metodologi untuk memperoleh pengetahuan dari data. FP-growth digunakan secara luas untuk menganalisa pola yang sering muncul dari jumlah data yang besar, dengan disertai dengan frekuensi. Pada penelitian ini, algoritma FP-grotwh digunakan untuk menganalisa salah satu cabang olah raga, yakni bulutangkis. Secara khusus, algoritma ini digunakan untuk mengidentifikasi pola dan kecenderungan pukulan seorang atlet selama pertandingan. Sebagai penutup, penerapan ilmu pengetahuan dalam dunia olah raga merupakan suatu keharusan, dalam rangka meningkatkan prestasi dalam turnamen besar. Hal inilah yang menjadi kepedulian kami dalam penelitian ini.
\end{abstract}

Kata Kunci: KDD, Algoritma FP Growth, bulutangkis

\section{Pendahuluan}

Bulutangkis merupakan olah raga yang populer di Indonesia. Cabang olah raga ini telah menghasilkan banyak prestasi yang membanggakan bagi negara kita. Oleh karena itu Indonesia perlu melakukan berbagai upaya terobosan, agar tetap kompetitif di dalam berbagai event internasional. Demi menjaga dan mempertahankan reputasi tersebut, Indonesia mau tidak mau harus menerapkan pengembangan olah raga ini secara sistematis dan terencana. Salah satunya adalah dengan mengembangkan program pelatihan yang memanfatkan teknologi IT sebagai analisa pertandingan berdasarkan ilmu pengetahuan (riset) untuk keolahragaan (sport science).

Pemanfaatan teknologi dalam bidang olah raga (sportscience) telah berkembang pesat. Salah satunya adalah proses scouting, pemandu bakat serta analisa proses pertandingan terhadap pemain lawan dilakukan dengan metode yang inovatif, demi mendongkrak prestasi sang atlet. Proses scouting sendiri dapat dilakukan sebelum, selama dan setelah pertandingan. Serangkaian analisa statistik dilakukan, sehingga memberikan pendekatan yang akurat dalam memahami kekuatan dan kelemahan lawan. Perkembangan setiap pemain dipantau dengan data akurat, serta diformulasikan dalam metode pelatihan yang efektif demi mendongkrak prestasi.

\section{II.TINJAUAN PUSTAKA}

\subsection{Bulu Tangkis}

Bulutangkis adalah suatu olahraga menggunakan raket dan shuttlecock yang dipukul untuk melewati sebuah jaring (net), sehingga shuttlecock jatuh di bidang permainan lawan. Dalam permainan ini teknik pukulan yang diguanakan adalah : 
a. Pukulan service / servis :

Pukulan servis dilaksanakan pada awal permainan, pukulan ini merupakan pukulan dengan raket yang bertujuan menerbangkan shuttlecock ke bidang lapangan lawan. Arah pukulan ini adalah menyilang (diagonal) dari bidang permainan. Dalam perkembangannya type pukulan ini adalah :
i. Pukulan servis pendek
ii. Pukulan servis panjang
iii. Pukulan servis mendatar
iv. Pukulan servis cambuk

b. Pukulan $l o b$

Pukulan $l o b$ merupakan teknik pukulan terhadap shuttlecock yang menghasilkan ketinggian maksimal serta membentuk sudut jatuh yang vertical mengarah ke garis belakang di bidang permainan lawan. Teknik ini dapat dilakukan dengan dua cara, yaitu:

i. Overhead lob, yaitu pukulan lob yang dilakukan dari atas kepala dengan cara menerbangkan shuttlecock melambung ke arah belakang.

ii. Underhand lob, yaitu pukulan lob yang dilakukan dari bagian bawah badan (pinggang), sehingga saat shuttlecock menuju bidang permainan lawan dalam posisi melambung setinggi mungkin, dan jatuh dengan kecepatan tinggi. Jika hal ini dilakukan berkombinasi dengan pukulan lain akan sangat menguras tenaga lawan.

c. Pukulan smash

Pukulan smash merupakan pukulan katagori menyerang yang bertujuan untuk menghujamkan shuttlecock secepat mungkin, dengan mengarahkan ke bidang lapangan lawan. Smash dilakukan dengan memotong sudut datangnya bola, saat sebelum mencapai titik tertentu, dilakukan dengan kekuatan penuh dan dilakukan secara tiba-tiba. Teknik pukulan ini akan menghasilkan bola dengan kecepatan tinggi dan membentuk sudut yang sangat tajam dengan bidang permainan lawan. Beberapa pemain juga memiliki kemampuan untuk melakukannya dengan dikombinasikan dengan pukulan backhand. Backhand adalah pukulan yang dilakukan pada sisi yang berlawanan dengan pegangan raket.

\subsection{Algoritma FP Growth}

Data mining adalah proses mencari pola atau informasi menarik berdasarkan hasil analisa dalam sebuah populasi data terpilih dengan menggunakan teknik atau metode algoritma tertentu ${ }^{[1]}$. FP Growth adalah salah satu algoritma apriori, yakni teknik data mining untuk menemukan aturan asosiasi antara suatu kombinasi item dengan mempertimbangkan frekuensi dari data. Relasi yang tersembunyi ini direpresentasikan dalam bentuk aturan asosiasi terhadap himpunan item yang seringkali muncul (frequent itemset).

Terdapat dua parameter yang digunakan untuk mengukur aturan asosiatif yaitu, support (nilai penunjang) yaitu persentase kombinasi item tersebut dalam database dan confidance (nilai kepastian), yaitu kuatnya hubungan antar item dalam aturan asosiatif ${ }^{[8]}$.

$$
\text { Support }(A)=\frac{\text { Jumlah Transaksi mengandung A }}{\text { Total Transaksi }}
$$

Confidance (c) merupakan ukuran seberapa sering item A muncul di transaksi yang mengandung item A'. Confidance dihitung setelah support ditentukan. Nilai confidance dari aturan A-> B dioperoleh dari rumus berikut:

$$
\text { Confidence }=P(B \mid A)=\frac{\text { Jumlah Transaksi mengandung A dan B }}{\text { Jumlah Transaksi mengandung A }}
$$

Algoritma Apriori dalam pemakaiannya dilaksanakan dengan mengurangi jumlah itemset yang diamati/dipertimbangkan. Pengguna menetapkan besaran minimum support yang dikehendaki. Perhitungan dengan algoritma Apriori pertama kali akan menghasilkan semua himpunan item yang memenuhi dukungan. Setelah ditetapkan besaran minimum support, akan diperoleh jumlah itemset yang terpilih. Himpunan item tersebut sering disebut himpunan item (frequent item sets) ${ }^{[8][9]}$. 


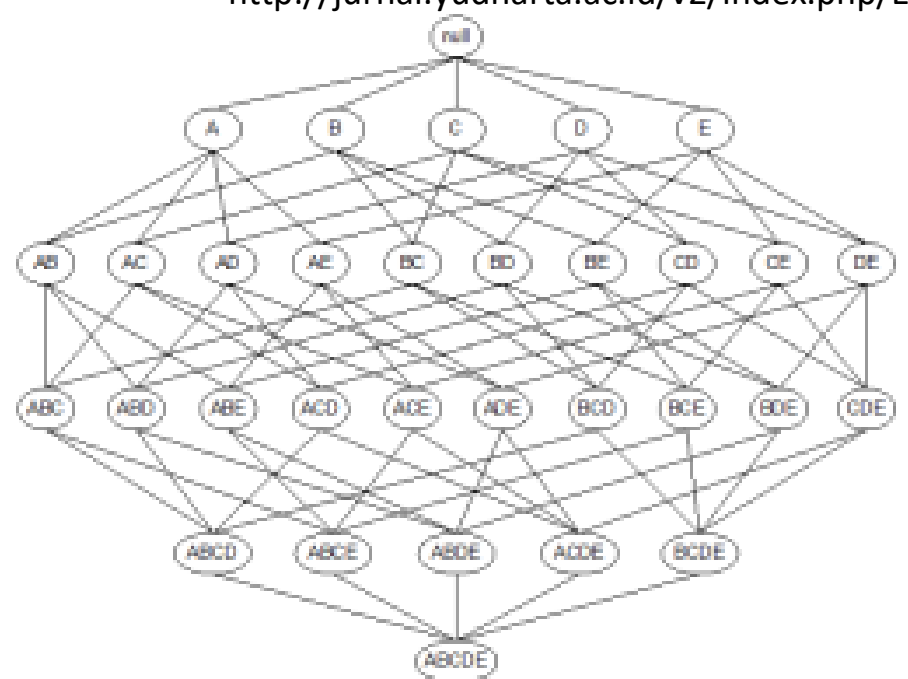

Gambar 1 : Model Frequent Item Set Generation

Frequent item set generation disajikan pada Gambar 1. Tahap pertama adalah mengoleksi semua itemset yang memenuhi syarat support $\geq$ minsup. Itemset-itemset ini disebut frequent itemset. Tahap kedua adalah rule generation, bertujuan membentuk aturan dengan nilai confidence yang tinggi dari frequent itemset yang telah diperoleh sebelumnya. Aturan ini disebut strong rules ${ }^{[8][9]}$.

Algoritma Frequent Pattern Growth (FP-Growth) merupakan pengembangan dari algoritma Apriori. Sehingga kekurangan dari algoritma Apriori diperbaiki oleh algoritma FP Growth ${ }^{[3]}$. FP-Growth adalah salah satu alternatif algoritma yang dapat digunakan untuk menentukan himpunan data yang paling sering muncul (frequent itemset) dalam sebuah kumpulan data ${ }^{[10]}$.

\section{METODOLOGI PENELITIAN}

\subsection{Study Literatur}

Pada tahapan ini, penulis melakukan kajian terhadap teori permainan bulutangkis, serta melakukan kajian terhadap algoritma yang cocok dengan model yang dikembangkan. Dalam hal ini, dipilih algoritma FP Growth. Dengan pertimbangan memperhitungkan bobot frekuensi yang berulan.

\subsection{Pengumpulan Data}

Data set yang diperoleh pada penelitian ini adalah kombinasi pukulan pertandingan bulu tangkis yang terdiri dari lob, net, dropshot, smash, backhand dan drive dalam satu game pertandingan bulu tangkis. Pada penelitian ini, pengumpulan data dilakukan dengan melakukan pengamatan terhadap video pertandingan bulutangkis tingkat internasional. Salah satu partai menarik yang menjadi bahan dalam penelitian ini adalah pengamatan terhadap pola pukulan yang dilakukan oleh atlet Indonesia, Jonathan Christie. Dalam pengamatan tersebut, penulis menggunakan pengamatan, yakni partai final antara Jonatan Christie/JC (Indonesia) vs Shi Yuqi (RRC) dalam kejuaraan Badminton Asia beregu putra tahun 2018.

\subsection{Analisis dan Disain}

Hasil data yang diperoleh dari pengumpulan data, selanjutnya dilakukan simulasi dan disain pemodelan dari data yang diperoleh. Perangkat lunak yang digunakan dalam simulasi adalah Tanagra ver 1.4. Hasil selanjutnya dari hasil perhitungan diperoleh beberapa pola yang dominan, yang memiliki frekuensi paling tinggi.

\section{HASIL DAN PEMBAHASAN}

\subsection{Data Set Pukulan Bulu Tangkis}

Berdasarkan hasil pengamatan video pertandingan pada set pertama ini, diperoleh data sebanyak 37 buah, yang terdiri dari 7 jenis pukulan. Dimulai dari service, netting, drop shot, lob, smash, backhand dan drive return. Data set selengkapnya disajikan dalam Tabel $1 \mathrm{sbb}$ : 


\section{JURNAL EXPLORE IT!}

Vol. 11 No. 1 - Juni 2019

p-ISSN 2086-3489 (Print)- e-ISSN 2549-354X (Online)

Avaiable online at

http://jurnal.yudharta.ac.id/v2/index.php/EXPLORE-IT/

Table 1 : Scouting Card Jonatan Christie (INA) vs Shi Yuqi (CHN)

\section{SCOUTING CARD}

\begin{tabular}{|c|c|c|c|c|c|c|c|c|c|c|}
\hline No & Skor JC & Skor SY & Serve & Netting & Drop Shot & Lob & Smash & Backhand & Prive Return & Total \\
\hline 1 & 0 & 0 & 1 & 2 & 1 & 4 & 0 & 0 & 1 & 9 \\
\hline 2 & 0 & 1 & 0 & 2 & 2 & 2 & 0 & 0 & 1 & 7 \\
\hline 3 & 1 & 1 & 1 & 4 & 0 & 1 & 2 & 1 & 0 & 9 \\
\hline \multirow[t]{3}{*}{4} & 2 & 1 & 1 & 1 & 0 & 1 & 0 & 0 & 0 & 3 \\
\hline & $\ldots$ & & & & & & & & & \\
\hline & $\ldots$ & & & & & & & & & \\
\hline 36 & 16 & 19 & 0 & 1 & 0 & 0 & 0 & 0 & 0 & 1 \\
\hline \multirow[t]{2}{*}{37} & 16 & 20 & 0 & 1 & 1 & 1 & 0 & 0 & 0 & 3 \\
\hline & 16 & 21 & game & & & & & & & 0 \\
\hline
\end{tabular}

Pengamatan yang dilakukan pada set pertama, dengan hasil akhir adalah 16-21 untuk keunggulan lawan. Pada set tersebut, JC melakukan 17 kali serve, dan lebih mengandalkan permainan pada jenis pukulan netting, drop shot dan lob $($ total $=67 \%)$.

Table 2 : Scouting Card Resume Jonatan Christie (INA) vs Shi Yuqi (CHN)

\section{SCOUTING CARD RESUME}

\begin{tabular}{|c|c|c|c|c|c|c|c|c|}
\hline Date & : unknown & & & & & & & \\
\hline Event & \multicolumn{5}{|c|}{ : Final Badminton Asia Team Championship 2018} & & & \\
\hline Venue & \multicolumn{4}{|c|}{ :Stadium Abd. Halim, Alor Setar, Malaysia } & & & & \\
\hline Scouting & \multicolumn{3}{|c|}{ : Jonathan Christie (INA) } & & & & & \\
\hline Opponent & \multicolumn{2}{|c|}{ :Shi Yuqi (CHN) } & & & & & & \\
\hline \multirow[t]{2}{*}{ Game } & \multicolumn{2}{|c|}{ : 1st Men Single / Set-1 } & & & & & & \\
\hline & Serve & Netting & Drop Shot & Lob & Smash & Backhand & Drive Return & Total \\
\hline Total & 17 & 61 & 46 & 43 & 18 & 20 & 18 & 223 \\
\hline Avg & 0,46 & 1,65 & 1,24 & 1,16 & 0,49 & 0,54 & 0,49 & 6,03 \\
\hline Min & 0 & 0 & 0 & 0 & 0 & 0 & 0 & 1 \\
\hline Max & 1 & 5 & 7 & 7 & 3 & 4 & 2 & 22 \\
\hline Tactical & $8 \%$ & $27 \%$ & $21 \%$ & $19 \%$ & $8 \%$ & $9 \%$ & $8 \%$ & $100 \%$ \\
\hline
\end{tabular}

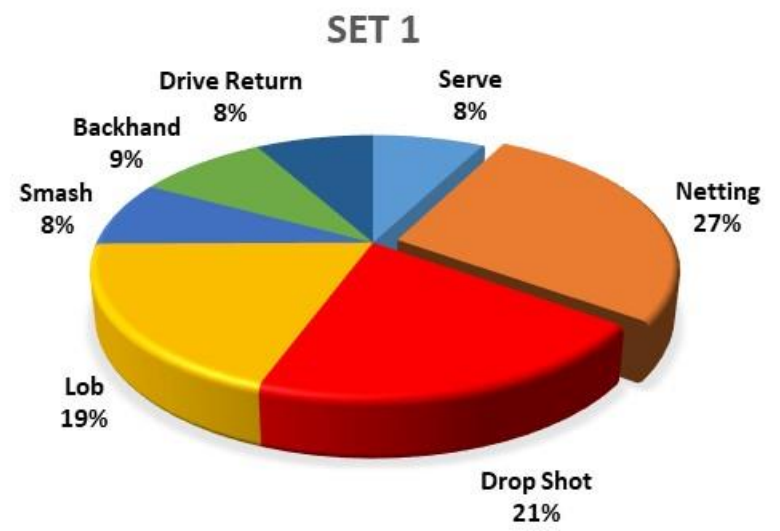

Gambar 2 : Resume Pola Permainan Jonathan Christie SET 1

\subsection{Simulasi dan Analisa Data}

Selanjutnya dilakukan analisa untuk mengetahui pola permainan JC dalam set 1 dengan menggunakan frequent itemsets. Minimum support yang dikehendaki adalah 25\%, hal ini dimaksudkan untuk memberikan batas minimal pengamatan terhadap pola pukulan beruntun yang dilakukan oleh JC selama bertanding pada set 1 . Parameter selengkapnya yang digunakan dalam perhitungan ini disajikan dalam Gambar 3.

Hasil perhitungan dengan menggunakan frequent itemsets memberikan 8 pola dominan dalam permainan JC dalam set 1, seperti disajikan dalam Gambar 4. Lob dan dilanjutkan dengan dropshoot adalah pola permainan baik menyerang maupun bertahan yang diterapkan oleh JC dalam set 1 ini. Hal ini sangat dominan oleh karena mencapai 
48,6 \%. Dari sejumlah lob dan dropshoot tersebut, 37,8\% dilanjutkan dengan netting. Pola pukulan selanjutnya yang dilakukan oleh JC adalah Lob dilanjutkan dengan Netting dan dropshoot dilanjutkan dengan netting yang dominan. Sedangkan setelah melakukan servis, JC sering melakukan kombinasi pukulan dengan pukulan netting.

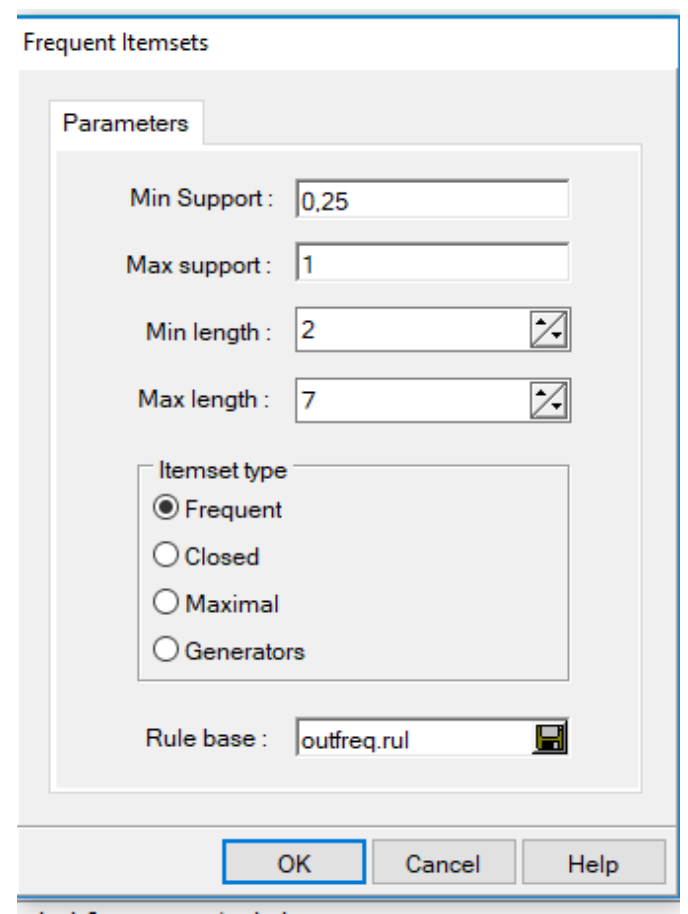

Gambar 3 : Parameter Frequent Itemsets

\begin{tabular}{|c|c|c|}
\hline \multicolumn{3}{|c|}{ Execution $\log . .}$. \\
\hline \multicolumn{3}{|c|}{ 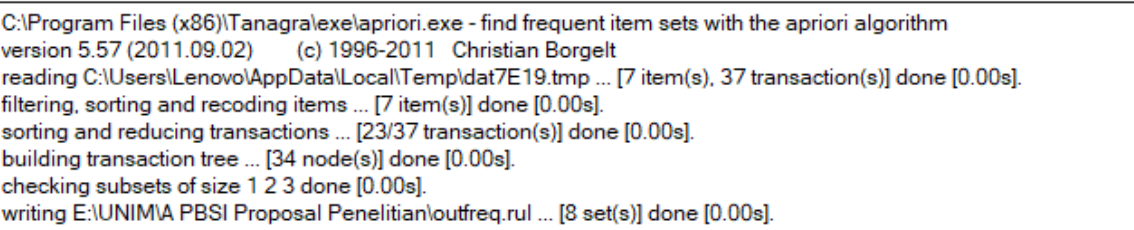 } \\
\hline \multicolumn{3}{|c|}{ ITEMSETS [\#8 itemsets loaded] } \\
\hline $\mathrm{N}^{*}$ & Description & Support \\
\hline 1 & Smash $/$ Netting & 27,0 \\
\hline 2 & Serve $\wedge$ Lob & 32,4 \\
\hline 3 & Serve $\curvearrowright$ Drop_Shot & 29,7 \\
\hline 4 & Serve $\wedge$ Netting & 32,4 \\
\hline 5 & Lob $\triangle$ Drop_Shot & 48,6 \\
\hline 6 & Lob $\triangle$ Drop_Shot $\triangle$ Netting & 37.8 \\
\hline 7 & Lob $\curvearrowright$ Netting & 45,9 \\
\hline 8 & Drop_Shot N Netting & 45,9 \\
\hline
\end{tabular}

\section{Gambar 4 : Hasil Perhitungan Frequent Itemsets}

Berdasarkan hasil tersebut, terlihat bahwa pola permainan JC sangat mengandalkan 3 jenis kombinasi utama, yaitu : Lob dilanjutkan dengan Drop Shot, Lob dilanjutkan dengan Netting, Drop Shot dengan Netting. Pada set ini diperoleh hasil akhir berupa kekalahan dengan skor 16-21. Variasi pukulan alternative yang bias dilakukan adalah bermain smash (cepat), atau divariasikan dengan lob serang (rally panjang).

\section{KESIMPULAN DAN SARAN}


JURNAL EXPLORE IT!

Vol. 11 No. 1 - Juni 2019

p-ISSN 2086-3489 (Print)- e-ISSN 2549-354X (Online)

Avaiable online at

http://jurnal.yudharta.ac.id/v2/index.php/EXPLORE-IT/

\subsection{Kesimpulan}

1. Berdasarkan hasil perhitungan dan analisa dengan menggunakan fp-growth diperoleh kesimpulan bahwa pola permainan JC sangat monoton pada set 1. JC lebih mengandalkan dengan Lob, Netting dan Dropshoot untuk mengalahkan lawan.

2. FP-growth mampu memberikan gambaran tentang pola permainan seorang atlet bulutangkis pada suatu permainan.

\subsection{Saran}

1. Seorang atlet bulu tangkis tidak hanya membutuhkan fisik dan kemampuan teknis dalam bertanding di tingkat kompetisi yang tertinggi. Namun juga membutuhkan karakter permainan yang mampu mempengaruhi cara bermain lawan, sekaligus tidak terpengaruh oleh cara bermain yang dikehendaki lawan. Selain itu juga membutuhkan kreativitas untuk memberikan efek kejut bagi lawan.

\section{DAFTAR PUSTAKA}

1. Affriantari Rochmah., (2010). "Perbandingan algoritma apriori dan Algoritma FP Growth dalam Optimasi Penentuan Frequent Itemset". FT UNS, Solo.

2. Bompa. 1990. "Theory and Methodology of Training.", Dubugus, Iowa: Kendall. Hunt Publishing Company

3. David Samuel, (2008). "Penerapan Stuktur FP-Tree dan Algoritma FP Growth dalam Optimasi Penentuan Frequent Itemset. " Bandung: Institut Teknologi Bandung.

4. Falani, Achmad Zakki. (2011). Knowledge Discovery in Database: Data Mining, accessed 2013-04-21.

5. Goldie Gunadi., dan Dana Indra Sensuse.. 2012."Penerapan Metode Data Mining Market Basket Analysis Terhadap Data Penjualan Produk Buku Dengan Menggunakan Algoritma Apriori Dan Frequent Pattern Growth (Fp-Growth) : Studi Kasus Percetakan PT. Gramedia." Jurnal TELEMATIKA MKOM. 1 (1). 118 132.

6. Han, Jiawei, Kamber M., (2001), Data Mining: Concepts and Techniques, Morgan Kaufmann Publishing Series, Elsevier, Waltham, MA 02451, USA, ISBN-13: 978-0123814791, $3^{\text {rd }}$ edition.

7. Hipp, J.; Güntzer, U.; Nakhaeizadeh, G. (2000). "Algorithms for association rule mining --- a general survey and comparison". ACM SIGKDD Explorations Newsletter2: 58.t

8. K. Ali, S. Manganaris, and R. Srikant. (August 1997). Partial Classification using Association Rules. In Proc. Of $3^{\text {rd }}$ Intl. Conf. on KDD and Data Mining, pages 115-118, Newprot Beach, CA,

9. Kusrini, Luthfi, E.T., (2009). "Algoritma Data Mining. “, Andi Offset. Surabaya.

10. Larose, Daniel T, (2006). "Data Mining Methods and Models." Hoboken New Jersey: Jhon Wiley\& Sons, Inc. 